\title{
Discussion on urban road traffic congestion algorithm for automatically determining
}

\author{
Shanshan Qu ${ }^{1,}$, Zhikai Cheng \\ Liaoning Police College, Liaoning, Dalian 116036, China \\ paperiset@163.com
}

\begin{abstract}
Keywords: Urban roads, jams judgment, reach / discrete functions, delays
Abstract. Abstract: Compared with expressway, most of the traffic flow in urban road network can be denoted as interrupted traffic flow. Based on the currently employed equipment for traffic flow collection and traffic signal control in urban roads, different types of traffic flow in urban roads is analyzed with the traffic flow arrival/departure model in transportation engineering. Mathematical models complying with traffic flow changes are utilized to match the traffic flow in both entry and exit road blocks, thus enabling the automatic detection of traffic incident. This algorithm serves as a measure for the automatic judgment of urban road congestion and the expansion utility of intelligent transportation facilities in urban areas.
\end{abstract}

\section{Introduction}

At present the algorithm used to determine congestion mostly used in high speed Highway, traffic flow characteristics to which it applies are basically continuous stream Non-stop state. With actual observations of each inspection Traffic flow parameters measured points or sections were analyzed and compared, and then judge Location of the incident and severity [1]. However, due to the presence of a large number of urban road network intersections, its traffic flow, The basic rooms are all drying up, and therefore suitable for highway congestion sentence Off the road in the city the basic algorithm cannot be applied. But the city owned road Blocking situations need more intelligent, more timely detection and disposal. Therefore, with the current urban intelligent traffic detection equipment and Application Status signal control equipment, the paper sentenced urban traffic congestion Broken proposes a new algorithm [2].

\section{Loop and signal control equipment Comprehensive Utilization}

Comprehensive Utilization of coils and signal control equipment, is split don't use coils and number of real - time traffic flow signal control equipment acquisition [3]. According to arrival and discrete functions of traffic engineering and traffic matches, makes sense Calculation Model for Traffic flow within a certain time, and makes sense Determine thresholds that are compared to historical data, and congestion test Measuring. Essentially two different saturation, so can be used for comparative analysis of traffic data only traffic (Table 1). 


\begin{tabular}{|c|c|c|c|}
\hline Category & Acquisition cycle & position & Content \\
\hline Coil & $\begin{array}{c}\text { 10,30 s, etc.can be } \\
\text { manually set acquisition } \\
\text { cycle }\end{array}$ & $\begin{array}{l}\text { From the intersection } 100 \\
\qquad \mathrm{~m} \sim 150 \mathrm{~m}\end{array}$ & $\begin{array}{l}\text { Traffic volume, average } \\
\text { speed, Lane share, the } \\
\text { average time headway, the } \\
\text { average headway, vehicle } \\
\text { lengths, models }\end{array}$ \\
\hline scats & $\begin{array}{c}5 \text { min, } 15 \text { min, can be } \\
\text { manually set acquisition } \\
\text { cycle }\end{array}$ & $\begin{array}{l}\text { After turning on the Stop } \\
\text { line } 1 \mathrm{~m}\end{array}$ & Traffic saturation \\
\hline
\end{tabular}

\section{Traffic to Get / Discrete Functions}

Due to the different characteristics of urban road traffic flow, at different times Sex, in order to ensure accurate algorithm for automatically determining traffic jam And so, according to the different characteristics of urban roads at different times to pay Select a different traffic flow characteristics and to the distribution and flow of discrete points The chief function[4].

The basic formula: $P(x)=\frac{(\lambda t)^{x} e^{-\lambda t}}{x !} \quad x=0,1,2 \ldots$, The actual application, often using this formula, $P(x)=\frac{m^{x} e^{-m}}{x !}$, where, $m=\lambda t$ is counting cycle. Using the Poisson distribution fitting data, the parameters press the calculation, $m=\frac{\text { Observation of the total number of vehicles }}{\text { Total number of cycles }}$.

$$
=\sum_{i=1}^{g} x_{i} f_{i} / \sum_{i=1}^{g} f_{i}=\frac{1}{N} \sum_{i=1}^{g} x_{i} f_{i}
$$

Vehicles crowded, traffic free exercise opportunities are few basic formula is: $\quad P(x)=C_{x}^{n}\left(\frac{\lambda x}{n}\right)^{n}\left(1-\frac{\lambda x}{n}\right)^{n-x}, x=0,1,2 \cdots \quad, \quad C_{x}^{n}=\frac{n !}{x !(n-x) !} \quad, \quad$ In $\quad$ practical application, $p=\lambda t / n$, so, $P(x)=C_{x}^{n} p^{x}(1-p)^{n-x} \cdots \cdots 0<p<1$.

Negative binomial, When the amount of fluctuation of the applicable conditions to reach larger vehicles, such as upstream from close observation points have signalized intersections, while counting period very short (shorter than the length of the green phase), the resulting number of vehicles arrive with a more large variance and obey negative binomial distribution.

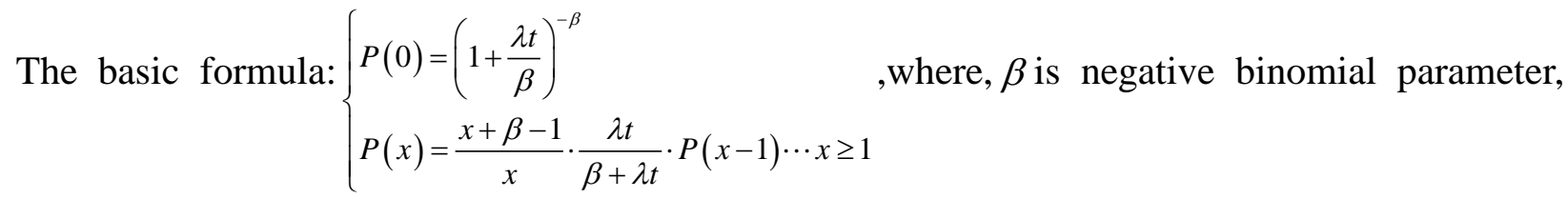
taking a positive real number. 


\section{Delay and queue length calculation functions}

Single lined multi-lane service: Refers to the number of cases lined up waiting for a team of service channels. Head of a queue of cars which channel whenever you visualize where to receive services. Multi-channel multi-queue service: each row represents one team for each channel, each channel corresponding to only one of its vehicle fleet service vehicles cannot arbitrarily change the team. This situation is equivalent to the $\mathrm{N}$-channel service system. For multi-channel service system to maintain a steady state condition is not $\rho<1$, but $\bar{\rho} / N<1 . \bar{\rho}$ where $\rho$ is the average of each channel. Each channel is currently considering the case of the P-value equal to $\bar{\rho}=\rho$. If $\lambda$ is into the system so that the average rate of the car, then line up for the one-way multi-channel service system, the presence of the following relationship: The average queue length $: \bar{g}=\bar{n}-p$, The average wait time in the queue $: \bar{W}=\bar{g} / \lambda$.

\section{Congestion decision algorithm options}

Coil single section congestion judgment through the coil form jam judged mainly by section analysis of historical data, determine the different circumstances in different times of the congestion of traffic flow threshold, the coil real - time traffic flow data collection and congestion threshold for comparison and analysis of road congestion conditions.

Coil real - time traffic flow analysis of data collected includes: Data and judgment, such as data preprocessing, calculation of Characteristic Parameters of traffic link, and the real - time traffic flow data storage, and a growing historical data, an amendment to the congestion of the dynamic threshold.

Judge sctas the intersection congestion similar coils single section judging process, but because scats the acquisition of the traffic parameters and coil different, but the same principle and process of judging (Fig. 1)

Coils and scats coil and scats comprehensive utilization of comprehensive estimation algorithm for congestion judgment, is through the analysis of the data collection on road winding, matched to meet the traffic to the function, and scats analysis of data collected through the intersection, matches except those that meet the traffic discrete functions, and to use delay and queue length calculation function to judge the congestion. 


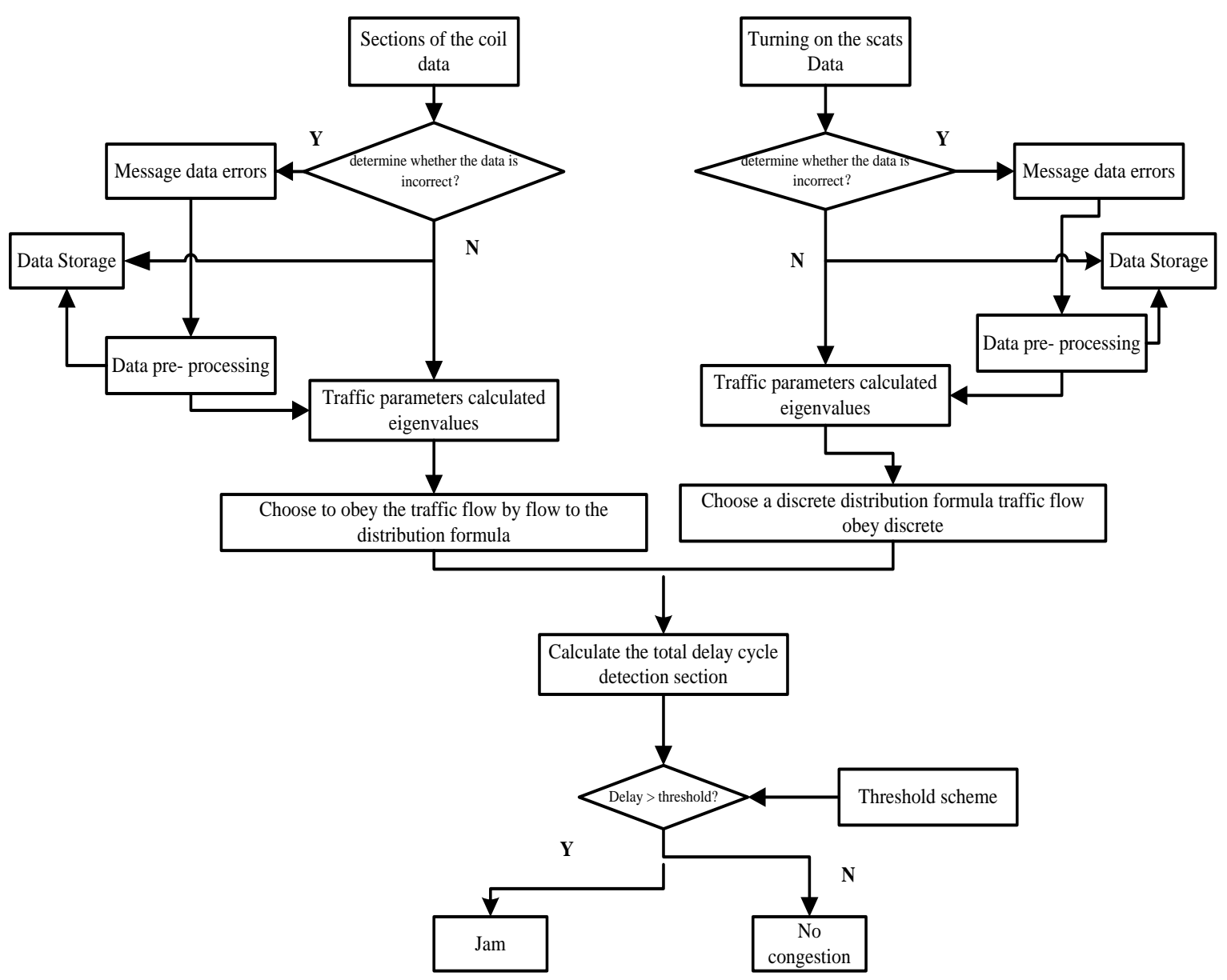

Fig. 1 Flow chart of incident detection by using loop and Scats

\section{Summary}

This article used to classify traffic and delays in traffic engineering terms Count function, combined with its phase of the current building in the city Close the facility, proposed congestion judgment mode, will separate systems linked to Common in urban traffic management services. Believe by urban roads Study on the congestion algorithm for automatically determining effective traffic flow collection The system works closely with the signal control system combines the city road Traffic Management Service investment and saving money.

\section{References}

[1] X.C. Xu and L. Liu: Technology\& Economy in Areas of Communications, Vol. 2 (2004), p.3.

[2] G.L. Tan and Z.F. Jiang: Journal of Xi'an Highway University, Vol. 3 (1999), p.3.

[3] STEPHANEDES Yorgos J, LIU Xiao: Artificial neural networks for freeway incident detection. J. Transportation Research Record 1494 TRB. Washington D C: National Research Council, 1995:91-97.

[2] Y.W. Zhang and Y.M. Liu: Journal of Yunnan Polytechnic University, Vol. 4 (1998), p.2. 